April - 2003

\title{
Research Notes
}

\section{Supporting Distance Students Using the Internet: A Brazilian experience}

\author{
Marialice de Moraes, Carolina Rodrigues Paz \\ Flavia Lumi Matuzawa, and Patricia Jantsch Fiuza \\ Federal University of Santa Catarina \\ Brazil
}

\section{Introduction}

The current context of globalization is marked by rapid and widespread technological, economic, and social changes, all of which raise important questions for educators. Described by such terms as 'knowledge explosion,' 'information era' and 'information hype,' we are living in an era where knowledge is evolving at a rapid speed, where students and teachers alike are called upon to quickly assume new skills, competencies, and knowledge. However, in spite of its positive economic impact on society a whole, skills and knowledge development are increasingly seen as a responsibility of individuals. Clearly the acquisition of new skills, competencies, and knowledge are essential for individuals to gain better and more lucrative employment opportunities in the new world economy. Therefore, both individuals and society must keep abreast with constant changes occurring in today’s global economy.

The Internet plays a fundamental role in this equation: Sixty percent of North American schools and universities use email. Ninety-four percent of Americans indicate education as a 'top priority' for governmental actions. Fifty percent of the students engaged in higher education today are 25 years of age or older (NEA, 2000).

Market-driven economies are demanding a highly skilled and knowledgeable workforce. To meet these demands, universities and educational institutions of all stripes are exploring strategic alliances and striking win-win partnerships. Such dynamic is taking place in India, a country where substantial investments are being made in educational disciplines like computing science, which is producing highly trained computer programmers readily employable in the global job marketplace. Thanks to India's foresightedness, that country is currently leapfrogging from a preindustrial society to a markedly digitized one.

With an eye on India's success, Brazil's Federal University of Santa Catarina (UFSC) Graduate Program in Engineering (PPGEP) in 1996 created the Distance Education Laboratory (LED). Investing heavily in new information and communication technologies for distance education (DE) purposes, the LED has identified, designed, and developed flexible course alternatives using a variety of DE media and models.

According to Barcia and Vianney (1998, p. 61)

"Using communication theories, the LED is developing research in order to find the most appropriate languages for the use of the Internet, videoconference, 
teleconference, video-lessons, CBT's, printed materials, fax and telephone in the distance education process. This process aims to stimulate in students their sense of responsibility for the learning process, and to improve the interfaces to promote a more efficient student-media, student-content, teacher- studentinstitution, student-teacher-tutoring, and student-students interaction, in the direction of establishing learning practice and a culture of collaborative learning."

The goal of this article is to examine the Internet in terms of the role it plays in supporting both distance education students and teachers.

\section{Internet and Distance Education}

Traditionally, distance education (DE) consisted of and used passive media such as print media, radio, and videotaped lessons, teaching and learning modes that often derive low potential for interactivity. Within the context of traditional DE delivery, interactivity occurred mainly through asynchronous correspondence between individual students and their instructors using print materials. With the advent of the Internet based technologies, however, DE practitioners now have at their fingertips technology that allows them to magnify and greatly enhance the quality of current DE models, thereby creating new and increased levels of interaction, communication, and collaboration among and between students, teachers, and their institution (Schrum, 1998). According to Harasim (1989) online course characteristics include independence of time and place, communication of many to many, collaboration of learning, and dependence in literal communication. Harasim also points to the many advantages of DE delivered via new technology: it allows for synchronous or asynchronous communication among students and teachers, regardless of time and space constraints, a condition which increases educational access to geographically isolated communities and interaction between diverse cultures.

According to Berge (1986), access to Internet-based technology, specifically late model computers and a trustworthy telecommunications infrastructure, is necessary for online DE instruction. Berge nonetheless considers technology as a secondary/ supportive player. Instead, he argues that careful construction and delivery of $\mathrm{DE}$ planning processes, including clear specification of learning objectives, must remain central to educational success. Internet technologies must be viewed as merely as the vehicle in which the interactions between the students and teachers travel, a means of intellectual transportation that helps people span geographic distances.

However, despite its increasingly widespread use (NEA, 2000), DE delivered via the Internet is not an easy task. Wiesenberg and Hutton (1996) cite some significant challenges to Internet delivery of DE. These challenges include the allocation of enough time necessary for planning, designing and offering of online DE courses; and the creation of dynamic virtual communities that encourages students to become independent learners capable of seeking out information from different sources. Students who study online at a distance must demonstrate greater control and responsibility in their learning processes. Writing must also be viewed an activity that allows students greater reflection (Harasim, 1990; Rohfeld and Hiemstra, 1994). Research also indicates that the addition of an online communication component integrated into traditional course models increases communication between student and teachers, which great enhances their levels of interactivity (Schrum, 1995; Schrum and Lamb, 1996; Stokes, 2000). It can therefore be said that electronic communication embodies features that naturally promote interaction and collaboration between different groups engaged in online learning.

On a macro level, the British Open University asserts that the delivery of DE using the Internet must embody a holistic vision, one in which DE learning culture is both acknowledged and given a supportive framework; development, design and delivery costs are realistically addressed; 
technological integration takes place between administrative and online DE learning/ teaching functions; and it is acknowledged that a fundamental transformation of pre-existing pedagogical and administrative practice will take place. In other words, new technology should not be used to repeat old practices (Thomas et al., 1998).

Because some students often do not possess the requisite Internet skills to fully and successfully participate in DE, different authors (Gladieux and Swail, 1999; Tomei, 1999) caution that some may not be ready to engage in online learning. As a result, institutions must be prepared to provide support so that their students can develop the necessary skills and abilities to engage in online learning. However, so as not to overwhelm, students must acquire online skills through gradual contact with the technology.

According to Tapscott (1995), Web-based technologies are facilitating the fundamental changes that are taking place at universities today. These changes include changes to the processes of teaching and learning at a distance.

Table 1. Past and Current/ Future of DE teaching and learning

\begin{tabular}{|l|l|}
\hline Past & Current /Future \\
\hline Physical classrooms & Virtual classrooms \\
\hline Focus in the teacher & Focus in the student \\
\hline content for the teacher (owner of the & student, for exchange with teacher and \\
knowledge) & colleagues \\
\hline Custo mized contents & Personalized contents \\
\hline Transmission of information & Facilitation of access to information \\
\hline Stand alone work & Group working \\
\hline Fixed calendar & Flexible calendar \\
\hline Centered organization & Decentralized organization \\
\hline Local & Global \\
\hline
\end{tabular}

\section{Supporting Students Using Internet Technologies}

Thanks to its pioneering efforts, the British Open University serves as a model for other institutions. In 1995, the British Open University made its first foray into the use of Web-based technologies to offer student support in areas such as electronic conferencing and the use of email for communication between students and tutors, primarily for evaluation purposes. The British Open University's early experiences revealed that a critical mass of online participants was essential for quality online interaction. The British Open University's experiences also revealed the tutors' central role as an active participant and facilitator, a human factor necessary for successful online learning outcomes (Thomas et al., 1998). Other research carried out at the British Open University (Price and Petre, 1997) indicated that students engaged in the online tutoring sessions, were:

- Acquiring skills like how to use course materials and suggested activities

- Determining course structure, goals, incentives, and project deadlines 
- Raising questionings and leveraging learning from other students’ study

- Confirming that they are on the right path and making progress towards their educational goals

- $\quad$ Seeking social contact with other students

Early research also showed that student support in online environments was only partially academic. A strong tendency toward socialization, a factor that allows students to build closer relationships with tutors and fellow students, was also evident.

\section{LED and the Use of Integrated Media}

To meet Brazil's increasing demand for flexible learning opportunities, University of Santa Catarina's LED is working to procure media designed for different pedagogical and administrative purposes. LED's objective is to expand and greatly enhance interaction of students, teachers, and colleagues through the use of integrated media technologies. To achieve this objective, LED is:

“. . . acquiring new technologies that are customized to balance the characteristics of its clients and Brazil's current technological reality, with the learning objectives of a given DE course. As a result, the University of Santa Catarina is using Integrated Media that incorporates not the latest most current media, but media used during first and second generations of DE” (Barcia et al., 2001).

The main purpose of the Integrated Media model, therefore, is to enhance all phases of student learning cycle by increasing and enhancing student/ teacher and student/ course content interaction. For instance, the University of Santa Catarina's masters programs employs a combination of videoconferencing, coupled with the Internet and/ or more traditional delivery modes such as print materials including articles, books, and study guides. Employing the Integrated Media model to enhance book-based learning activities, LED is engaged in such activities as guided reading exercises via videoconferencing.

The main purpose for applying the Integrated Media concept is to enhance interaction among students and teachers, technology and contents, during all moments of the teaching/ learning process. In the University of Santa Catarina's masters program, the media used, in order of preference, include videoconferencing, Internet, and printed material in the form of books, articles and guides, which in themselves are used to develop lessons for the videoconferencing sessions and stimulate students' interaction during guided reading activities.

The University's virtual learning environment is based on the metaphor of the classroom, and on the belief that students are independent adults capable of learning in both collaborative and individual settings. For this reason, the aim is to reproduce the same interactions that would normally occur in a traditional classroom.

With videoconferencing, the Virtual Classroom allows teachers to "teach face-to-face at a distance” (Cruz, 1996). Because this environment makes possible flexible learning using telecommunications as an exclusive educational delivery mode, traditional educational environments are undergoing change. "Distance" is no longer the most important factor; instead 'how communication takes place' is the most important. The new generation of DE requires "connections between people" and "communication applied to teaching-learning process" (Collis, 1995, p. 09). 


\section{Supporting Students via the Internet: The experience of the LED}

To support distance students' needs, the LED relies upon a team of monitors responsible for establishing direct, fast, and effective communication flow between and among students and teachers. This multidisciplinary team consists of graduate students engaged in DE research, and as such they are constantly researching new resources to expand upon the existing pedagogical framework of the Laboratory. Paralleling their research, this team also concerns itself with the adequate use of existing media, consolidating and integrating it to improve and enhance the teaching/ learning model developed by the Laboratory. In this context, the Internet is regarded a simply a tool to facilitate fast and efficient communication, a vehicle in which to arrive at institutional goals based on enhanced student support and monitoring. In the future, it is anticipated that the Internet may help diminish, and perhaps even eliminate, gaps between the forms of students support students/ teachers/ institutions are currently receiving and delivering, and what is actually desirable.

To build students' and teachers' a comfort levels in distance learning contexts, the support team offers both teachers and students instruction on 'how to' use the media along with general course overviews. Instruction targeting teachers focuses on equipment (e.g., computers, document camera, microphones and other videoconferencing equipment, etc.), as well as the didactic principles of teaching at a distance using videoconferencing technology. For students, face-toface instruction is offered at the beginning of the course, when monitors travel to the remote sites and conduct a two-day long seminars, where students' questions are addressed and answered on such topics as course content, Internet technology, videoconferencing etiquette, administrative details, etc. At this point, the monitor becomes the distance students' main contact, and is available to answer students' questions or concerns by telephone or videoconferencing from 8:00 am to 10:00 p.m. week days, or 24 hours per day, seven days a week, via asynchronous email.

To gauge students' abilities and aptitudes, as well as obtain basic information for course development purposes, a Student's Profile questionnaire was developed by the support team. To successfully complete this questionnaire, which must be accessed and completed online, students must possess minimum Internet skills, one of the basic necessities cited by Gladieux and Swail (1999), and Tomei (1999). Data collected include students' age, academic background, and levels of proficiency using Internet and videoconferencing technologies. The questionnaire also asks students qualitative questions about what compelled them to enroll in a particular course (e.g., for personal or professional interests).

From these data, the support team generates a report called the 'Group Profile.' The Group Profile report is subsequently forwarded to those responsible for course delivery (e.g., teachers: teaching and mentoring purposes); course coordinator; and local coordinator (i.e., institution partner). The Group Profile is also archived on the class website for students to access their personal information if they so desire. The Group Profile report has been of great value for teachers, because it provides them necessary background information to stay current with paced course syllabuses, determine when and where in a course to place emphasis, as well as alert them to students that may require special attention. With the recent digitalization of the University's course registration processes, this questionnaire is now a requisite document that students must complete prior to gaining admission to the Graduate Program in Production Engineering. Once students have completed all the necessary admission requirements, they receive a password to access their virtual classroom environment, as well as support websites that house the virtual library and interactive tools used in regularly scheduled extra-classroom activities and events.

The virtual learning environment also offers students' access to academic discussion forums, collaborative learning areas, a notice board for general course information, and a virtual 'Coffee House,' where they can socialize and relax in a virtual atmosphere. For example, using a 
comprehensive help menu, students can choose the option 'Talk to the Monitor' for administrative matters, obtain updates on their academic progress, and ask questions. If a question and its response are deemed of sufficient informational/ educational value to other students, they are transferred to a database, which can be accessed by others enrolled in the same course.

Email is another tool that facilitates interaction, communication, and information exchange. Indeed, in spite of the fact that the course website offers many interactive features, email remains the most popular mode of communication between and amongst students, monitors, and the University. Such easy-to-use features as the ability to file and archive messages, respond to queries asynchronously offline, program address books and mailing lists, etc., makes email a preferred choice for many students. When used correctly, email also motives, inspires, clarifies, and greatly reduces the sense of isolation often felt by distance education students and their monitors.

Experiencing higher degrees of proximity with their students - even those they have never met personally in face-to-face settings, monitors are able to greatly enhance and thus support students' distance learning experience. Via the use of new and emerging technologies, the team can monitor students' success through the entire duration of a course. To the end, the team is developing activities and procedures that can monitor student performance at all phases of the study cycle, information they will share with students to provide immediate, high quality feedback.

In short, the role of the support team is central to student support and thus to student performance, and success. This team and its technical infrastructures functions in such a way that they link teachers with students, with the underlying goal of better developing and stimulating student learning.

\section{Conclusion}

New information and communication technologies developed and designed specifically for educational purposes have greatly enhanced the development and quality distance education. To maximize potential techniques and to optimize new distance modalities of educational delivery, close coordination and ongoing exploration of new ways of providing enhanced student support are necessary. To this end, Brazil's Federal University of Santa Catarina LED support team has been working to exploit technological features that allow efficient communication and enhanced interaction among those involved in course delivery, from administrative planners, to teachers, to students. The choice and, more importantly, how educational media are used, are central considerations in the teaching/ learning equation.

The University's support team is currently concentrating its efforts on development of new processes that greatly improve currently available features. They are also seeking to increase students' overall access to Internet-based tools. The LED is likewise designing a database that archives and retrieves course-related information, thereby extending monitors' expertise to students at a time and place convenient to them. This database is growing daily, rapidly becoming an extensive repository of course-related knowledge, tips, and templates.

The support team is also looking to the future; they are currently modeling its next generation of virtual student monitoring and support environments.

The work of the University's support team is considered by many to be central to its distance educational offerings. In this modality of education, the monitor "is considered an important element in the communication network that ties the distance student to the institution. Around 90 percent of the remote institutions have a organization to offer support and direction to the students “ (Holmberg, 1985, pg. 19). 
In conclusion, investments being made by the Distance Education Laboratory (LED) to develop an efficient student support infrastructure based on technology and are considered central to Brazil's Federal University of Santa Catarina University future success in distance education initiatives.

\section{References}

Barcia, R., and Dulce, C. (1996). A videoconference an education continued em engenharia: a experience de Santa Catarina” Paper presented at the WFEO/ CEE International Symposium, May. Rio de Janeiro.

Barcia, R. M., Vianey, J., Rodigues, R. S., Moraes, M., Spanhol, F., and Bittencourt, D. (2001). Graduate Studies at a Distance: The Construction of a Brazilian Model. In F. T. Tschang and T. Della Santa. Access to Knowledge: New Information Technologies and the Emergence of the Virtual University (p. 313). Oxford: Pergamon.

Berge, Z. L. (1995). The Role of the Online Instructor/ Facilitator. Retrieved March 31, 2003 from: http://www.emoderators.com/moderators/teach_online.html

Collis, B. (1996).Tele-learning in a Digital World: The future of distance learning. London: Thomson.

Gladieux, L. E., and Swail, W. S. (1999). The virtual university and educational opportunity. Washington, DC.: The College Board. Retrieved April 7, 2002 from: http://www.ed.gov/offices/AC/ACSFA/april.pdf

Harasim, L. (1989). On-Line Education: A New Domain. In R. Mason and A. Kaye (Eds.) Mindweave: Communication, computers and distance instruction. Oxford: Pergamon Press. Retrieved June 17, 2002 from: http://icdl.open.ac.uk/literaturestore/mindweave/mindweave.html

Holmberg, B. (1985). Educación a Distancia: Situación e Perspectivas. Buenos Aires: Editorial KPELUSX.

NEA (2000). A Survey of Traditional and Distance Learning Higer Education Members. National Education Association. Retrieved April 7, 2002 from: www.nea.org/he

Price, B. A., and Petre, M. (1997). Large-Scale interactive Teaching via the Internet: experience with problem sessions and practical work in university courses. Proceedings from the 1997 EDMedia - EDTelecom Conference.

Rohfeld, R. W., and Hiemstra, R. (1994). Moderating Discussions in the Electronic Classroom. In Z. L. Berge and M. P. Collins (Eds.) Computer-Mediated Communication and the Online Classroom, Vol. III: Distance Learning. Cresskill, NJ.: Hampton Press.

Schrum, L. (1998). On-Line Education: A Study of Emerging Pedagogy. In B. Cahoon (Ed.) Adult Learning And The Internet. New directions for Adult and Continuing Education, Number 78. San Francisco: Jossey-Bass.

Schrum, L., and Lamb, T. (1996). A Groupware for Collaborative Learning: A Research Perspective on Processes, Opportunities, and Obstacles. Journal of Universal Computer Science 2(10), 717 - 731. 
Schrum, L. (1995). Educators and the Internet: A Case Study of Professional Development. Computers and Education 24(3), 221 - 228.

Stokes, S. (2000). Preparing Students to Take Online Interactive Courses. The Internet and Higher Education 2(2-3), 161 - 169.

Tapscott, D. (1995). The Digital Economy: Promise and peril in the age of networked intelligence. New York: McGraw Hill.

Thomas, P., Carswell, L., Price, B., and Petre, M. (1998). A holistic approach to supporting distance learning using the Internet: transformation, not translation. Proceedings of the 1998 EDmedia Conference.

Tomei, L. A. (1999). Concentration and infusion: Two approaches for teaching technology for lifelong learners. T.H.E. Journal 26(9), 72 - 76.

Wiesemberg, F., and Hutton, S. (1996). Teaching a Graduate program using Computer-Mediated conferencing Software. Journal of Distance Education 11(1), 83 - 100.

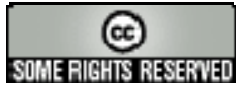

